Check for updates

Cite this: RSC Adv., 2017, 7, 30687

\title{
Exploration of polyepoxysuccinic acid as a novel draw solution in the forward osmosis process
}

\author{
Chen Wang, ${ }^{a}$ Baoyu Gao, (D) *a Pin Zhao, ${ }^{a}$ Ruihua Li, ${ }^{a}$ Qinyan Yue ${ }^{a}$ \\ and Ho Kyong Shon ${ }^{\mathrm{b}}$
}

Polyepoxysuccinic acid (PESA) is a green corrosion scale inhibitor. When PESA is used for wastewater desalination in the forward osmosis (FO) process, the diluted PESA solution could be used for cooling systems. In our investigation, the effects of membrane orientation, temperature and flow rate on FO performance are studied using PESA as a draw solute. The results show that the effect of temperature on water flux is obvious, but the water flux increase is higher from $25^{\circ} \mathrm{C}$ to $35^{\circ} \mathrm{C}$ than that from $35{ }^{\circ} \mathrm{C}$ to $45^{\circ} \mathrm{C}$. Compared to the $\mathrm{FO}$ mode, the water flux increases faster in the pressure-retarded osmosis mode (PRO mode) at high flow rate due to the reduction of concentrative internal concentration polarization (CICP). Compared with polyaspartic acid (PASP) and $\mathrm{NaCl}$, the water flux of PESA is the lowest under the same conditions. However, PESA has the lowest specific reverse solute flux $\left(J_{s} / J_{w}\right)$ at both membrane orientations. For example in the $\mathrm{FO}$ mode this value is $0.46 \mathrm{~g} \mathrm{~L}^{-1}$, whereas that of $\mathrm{NaCl}$ and PASP is 1.12 and $0.74 \mathrm{~g} \mathrm{~L}^{-1}$, respectively. This means that PESA has lower loss to the feed side than $\mathrm{NaCl}$ and PASP in the FO process, which greatly reduces the replenishment cost of the draw solute. The use of PESA as the draw solute in the FO process to treat dyeing water has the advantages of stable water flux (within $20 \mathrm{~min}$ ), high dye rejection (nearly 1) and reversible membrane fouling (restored to 97\%). The nanofiltration (NF) process indicates the good performance of PESA recovery with a high specific water flux (0.94 LMH per bar) and rejection rate (97.8\%). Thus, the overall performance of PESA demonstrates that it is a promising draw solute.

Received 9th April 2017

Accepted 31st May 2017

DOI: $10.1039 / c 7 r a 04036 a$

rsc.li/rsc-advances energy requirement, high salt rejection and low membrane fouling. ${ }^{10,11}$ Currently, FO is widely applied in brackish water/ seawater desalination, ${ }^{12-14}$ sludge dewatering, ${ }^{15-17}$ and pharmaceutical factory. ${ }^{18}$ However, its development is still hampered by two key factors, which are an ideal FO membrane and efficient draw solution. An excellent FO membrane should have the following properties: high water flux, high rejection of solutes and good anti fouling performance. Good draw solutes should have the features of high solubility, non-toxicity, low reverse solute flux, compatibility with the membrane, and easy recovery. ${ }^{19-21}$ Compared to the rapid development and nearly commercialization of FO membranes, ${ }^{22-24}$ finding an appropriate draw solute becomes critical.

Various draw solutions have been studied over the last few decades. The conventional inorganic salts such as $\mathrm{NaCl}$ generate a high water flux, but serious reverse solute leakage and the difficulty of draw solution recovery increase the operational costs. ${ }^{25}$ Ammonium bicarbonate produces high osmotic pressure and is easily recycled by distillation at around $60{ }^{\circ} \mathrm{C}$, but $\mathrm{NH}_{3}$ is difficult to remove to a drinkable level. ${ }^{12,26}$ It was reported that magnetic nanoparticles as draw solutions make it easier to recover draw solutes. However, particle aggregation during recycling is a problem. ${ }^{8}$ Hydrogels were found to be environmentally friendly when used as draw solutes. However,
${ }^{a}$ Shandong Provincial Key Laboratory of Water Pollution Control and Resource Reuse, School of Environmental Science and Engineering, Shandong University, Jinan 250100, China. E-mail: baoyugao_sdu@aliyun.com; Fax: +8653188364513; Tel: $+8653188366771$

${ }^{b}$ School of Civil and Environmental Engineering, University of Technology, Sydney (UTS), Post Box 129, Broadway, NSW 2007, Australia 
they have a poor water recovery rate and are unsuitable for practical application. ${ }^{27}$ Furthermore, several inorganic salts that can also serve as fertilizers were used as draw solutes. The diluted draw solutes can be used for agricultural irrigation, therefore the recovery of these solutes is unnecessary. However, the final diluted solutes are usually higher than the acceptable level for fertilization, and thus require a large amount of water to reduce their concentrations., ${ }^{\mathbf{4 , 2 8}}$ In a previous paper, a novel bulky hydroacid complex $\mathrm{Na}_{4}\left[\mathrm{Co}\left(\mathrm{C}_{6} \mathrm{H}_{4} \mathrm{O}_{7}\right)_{2}\right] \cdot 2 \mathrm{H}_{2} \mathrm{O}(\mathrm{Na}-\mathrm{Co}-\mathrm{CA})$ was synthesized as the draw solute in FO, which showed high water flux and high rejection to remove heavy metal ions from wastewater. ${ }^{29}$ However, it is still necessary to explore more suitable draw solutes.

Recently, polyelectrolytes as draw solutions have been gaining much interest. They can dissolve well in water, which guarantees high osmotic pressure with high water flux. Besides, polyelectrolytes with expanded structures reduce reverse solute leakage and make the recovery easier. Long et al. ${ }^{30}$ used a onestep Mannich-like reaction to synthesize a series of organic phosphonate salts (OPSs) and applied them as draw solutes in FO. Compared to $\mathrm{NaCl}$, they had a higher water flux and lower reverse solute flux. Nearly $92 \%$ rejection was achieved using a nanofiltration system to recover the diluted OPS solution. Ge et $a .^{3}$ studied different molecular weights of sodium salts of polyacrylic acid (PAA-Na) as draw solutes. They proved that the solution with the lowest molecular weight generated the highest water flux due to its low viscosity and high dissociation. Gwak et $a l .{ }^{31}$ investigated polyaspartic acid (PASP) as a draw solution in the FO process. Their results showed that PASP had a low reverse solute flux and comparable water flux. Besides, the reverse PASP solutes had a significant effect on reducing inorganic scaling. Wang et al. ${ }^{32}$ used carboxyethyl amine sodium salts (CASSs) as novel draw solutes in FO. When CASSs were used as draw solutes, a relatively higher water flux and lower reverse solute flux were achieved due to their relative high osmotic pressure and large molecule sizes.

The polyelectrolyte polyepoxysuccinic acid (PESA) is a green corrosion scale inhibitor, which has been used in many cooling water systems and shows excellent scale performance. When PESA is used for wastewater desalination in the FO process, the diluted PESA solution could be used in cooling systems, which not only saves water resources but also avoids the running cost of the subsequent recovery. In this work, PESA was chosen as the draw solution. It has significantly large molecular, good water soluble, non-toxic, and biodegradable features. This investigation is mainly comprised of four sections: (1) studying the chemical and physical properties of PESA. (2) Comparing its FO performance under different membrane orientations with $\mathrm{NaCl}$ and PASP draw agents. (3) Investigating its performance as a draw solution in the FO process under different concentrations, temperatures, cross flow rates, and membrane orientations using deionized (DI) water as the feed solution. (4) Studying the feasibility and applicability of using PESA as a draw solution for dyeing wastewater treatment and brackish water desalination. Additionally, the diluted PESA solution could be used in many cooling water systems. Besides, there are many processes such as membrane distillation, ultrafiltration and nanofiltration for regeneration of the PESA solution. ${ }^{33,34}$ It is envisioned that this study may provide fundamentals for the development of novel draw solutions for the FO process.

\section{Materials and methods}

\subsection{Forward osmosis membrane}

The membrane used in our study was a homemade polyamide thin film composite (TFC) FO membrane, which possesses various advantages such as high water flux and high salt rejection. However, its high reverse solute flux is a drawback. The physical and chemical properties of the membrane are presented in Table $1 .^{35,36}$ The contact angle of the TFC-FO membrane was less than $70^{\circ}$, which indicates that the membrane is hydrophobic. Contact angle was measured using a contact angle goniometer (JC2000C Contact Angle Meter, Shanghai Zhongchen Experiment Equipments Co. Ltd., China).

There are two different membrane orientations applied in the FO process. One orientation is described as the FO mode, in which the support layer faces the DS and the active layer faces the FS. The other orientation is called the pressure-retarded osmosis mode (PRO mode), in which the active layer faces the DS and the mechanical support layer faces the FS.

In order to have a clear observation of the TFC-FO membrane, micrographs of the membrane were obtained using a scanning electron microscope (HITACHI S-520). The active layer, support layer, and cross-section micrographs are shown in Fig. 1. The cross-section sample was cracked under flash freezing in liquid nitrogen. All the membrane samples were dried in a vacuum oven overnight.

\subsection{Feed and draw solution}

In the basic FO performance tests, deionized (DI) water was used as the feed solution. For the wastewater treatment experiments, dyeing wastewater and brackish water were used as the feed solutions. Reactive blue dye (K-GL) and disperse yellow (RGFL) were chosen as representatives of dyeing wastewater, which were obtained from the Jinan no. 2 Dyeing Mill, China. The name, maximum absorbance wavelength, $\mathrm{pH}$, zeta potential and molecular structure are shown in Table 2. The synthetic

Table 1 The physical and chemical properties of the TFC-FO membrane

\begin{tabular}{|c|c|c|c|c|c|}
\hline Sample & $\begin{array}{l}\text { Active layer } \\
\text { material }\end{array}$ & \multicolumn{2}{|c|}{ Contact angle $\left(^{\circ}\right)$} & $\begin{array}{l}\text { Zeta potential }(\mathrm{mV}) \text { at } \\
\text { active layer }\end{array}$ & Operating $\mathrm{pH}$ \\
\hline
\end{tabular}



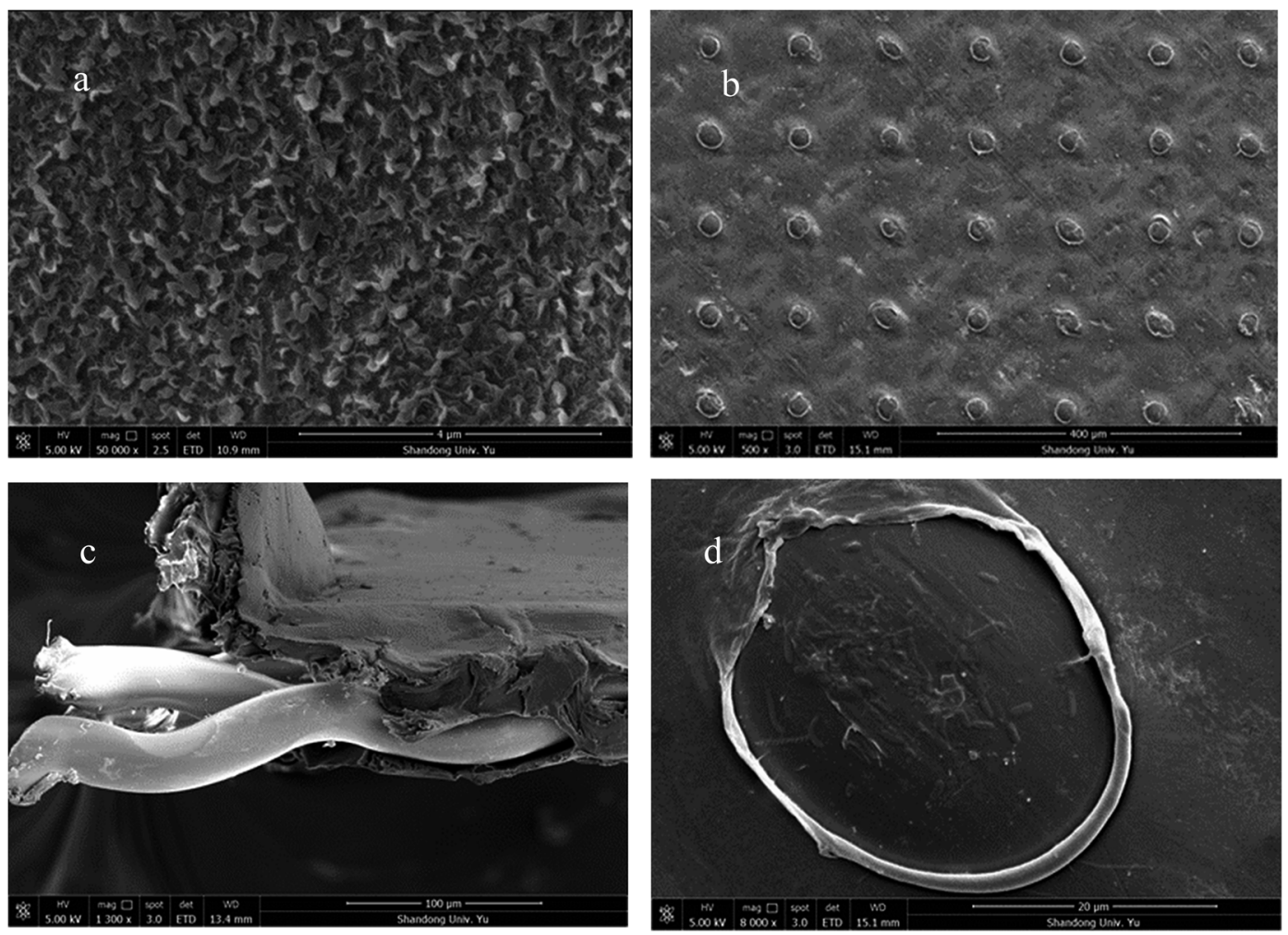

Fig. 1 SEM images of the TFC-FO membrane: (a) general view of the active layer, (b) general view of the support layer, (c) cross-section and (d) hole in the support layer.

Table 2 Characteristics of the dyes

$\begin{array}{llll}\mathrm{Name} & \begin{array}{l}\mathrm{Zeta} \text { potential } \\ (\mathrm{mV})\end{array} & \begin{array}{l}\text { Wave length } \\ (\mathrm{nm})\end{array} \\ \text { Reactive blue (K-GL) } & 6.0 & -35.6 & \\ \text { Disperse yellow (RGFL) } & 5.4 & -55.7\end{array}$

dyeing wastewater was prepared by adding $0.2 \mathrm{~g}$ dye to $1 \mathrm{~L}$ DI water and the concentration was similar to that of the actual wastewater. The synthetic brackish water $(0.3 \mathrm{M} \mathrm{NaCl})$ was prepared by adding $17.55 \mathrm{~g} \mathrm{NaCl}$ salt to $1 \mathrm{~L}$ DI water. $\mathrm{NaCl}$ was obtained from Sinopharm Chemical Reagent Co., Ltd (Shanghai). The PESA draw solution was obtained from the Shandong Xintai Water Treatment Technology Co., Ltd and Table 3 shows its physicochemical characteristics. PESA is colorless or transparent amber liquid with a relatively large molecular weight ranging from 400 to 1500 . The osmotic pressure of PESA was measured using a freezing point osmometer (Germany Löser). The viscosities of PESA under different concentrations and temperatures were measured using an Ubbelohde viscometer (1835 0.3-0.4 mm, Shanghai Bolea Instrument \& Equipment Co., Ltd). The relative viscosity of PESA, $\eta_{\gamma}$, compared to DI water is calculated using the equation

$$
\eta_{\gamma}=\frac{t_{1}}{t_{0}}
$$

where, $t_{1}$ and $t_{0}$ are the elution time of the polyelectrolyte solution and DI water, respectively. 
Table 3 The physical and chemical properties of PESA

Appearance $\left(25^{\circ} \mathrm{C}\right)$

Molecular formula Molecular weight
Colorless or transparent amber liquid $\mathrm{HO}\left(\mathrm{C}_{4} \mathrm{H}_{2} \mathrm{O}_{5} \mathrm{M}_{2}\right)_{\mathrm{n}} \cdot \mathrm{H}$ 400-1500
Density $\left(20^{\circ} \mathrm{C}\right) \mathrm{g} \mathrm{cm}^{-3}$

$\mathrm{pH}\left(25^{\circ} \mathrm{C}, 1 \%\right.$ solution $)$

Solid content $\%$

\subsection{Forward osmosis system}

Fig. 2 displays a schematic drawing of the FO setup used in our studies, which is similar to that in previous studies. ${ }^{33,37}$ The effective membrane area of the lab-scale membrane unit was $20.0 \mathrm{~cm}^{2}$ (7.7 $\mathrm{cm}$ length, $2.6 \mathrm{~cm}$ width and $0.3 \mathrm{~cm}$ depth). The feed and draw solutions were circulated by two pumps and flowed concurrently at different flow rates. A water bath controlled by a temperature control unit was used to adjust the temperatures of both the feed and draw solutions. A weight balance (Satorius Weighing Technology $\mathrm{GmbH}$, Gottingen, Germany) was used to record the weight of the draw solution for the computation of water flux. The original volumes of both the feed and draw solutions were $1 \mathrm{~L}$ in our experiments.

\subsection{Measurement of water flux and reverse solute flux}

2.4.1 Water flux. Water flux is calculated using the following equation:

$$
J_{\mathrm{w}}=\frac{\Delta m}{A \times \Delta t \times \rho}
$$

where, $J_{\mathrm{w}}$ is the water flux in the experiments, $\mathrm{L}\left(\mathrm{m}^{-2} \mathrm{~h}^{-1}\right)$ (LMH); $\Delta m$ is the measured weight interval for the water that permeated from the FS to the DS; $A$ is the effective area of the TFC-FO membrane; $\Delta t$ is the measuring time interval and $\rho$ is the density of water.

2.4.2 Reverse salt flux. Reverse salt flux is calculated using the following equation:

$$
J_{\mathrm{s}}=\frac{C_{t} \times V_{t}-C_{0} \times V_{0}}{A \times \Delta t}=\frac{C_{t}\left(V_{0}-J_{\mathrm{w}} \times A \times \Delta t\right)-C_{0} \times V_{0}}{A \times \Delta t}
$$

where, $J_{\mathrm{s}}$ is the reverse salt flux in the FO process, $\mathrm{g}\left(\mathrm{m}^{-2} \mathrm{~h}^{-1}\right)$ (gMH); $A$ is the effective area of the TFC-FO membrane; $\Delta t$ is the time interval; $V_{0}$ and $V_{t}$ are the initial and final volumes of the FS, respectively; and $C_{0}$ and $C_{t}$ are the initial and final salt concentrations of the FS, respectively.

\subsection{Nanofiltration process}

$\mathrm{NF}$ experiments were conducted using a lab-scale cross-flow filtration unit (FlowMem-CF042SS, USA). The commercial NF membrane NF-90 with an effective filtration area of $40.5 \mathrm{~cm}^{2}$ was used in our experiments. More details about the membrane are shown in Table 4 . The feed solution (PESA solution) with a concentration of $0.03 \mathrm{~g} \mathrm{~mL}^{-1}$ was filtrated at the operating pressure of $20 \mathrm{bar}$ and temperature of $25 \pm 1{ }^{\circ} \mathrm{C}$. Before each test, a new membrane was soaked in DI water overnight. The water flux was calculated using eqn (2). The solute rejection is calculated by the following equation:

$$
R=\left(1-\frac{C_{\mathrm{p}}}{C_{\mathrm{f}}}\right) \times 100 \%
$$

Table 4 Properties of commercial NF membrane

\begin{tabular}{ll}
\hline Property & NF-90 \\
\hline Pure water permeability (LMH per bar) & 6.48 \\
Top layer material & Polyamide \\
Feed water pH range & $2-11$ \\
Maximum applied pressure (psi) & 600
\end{tabular}

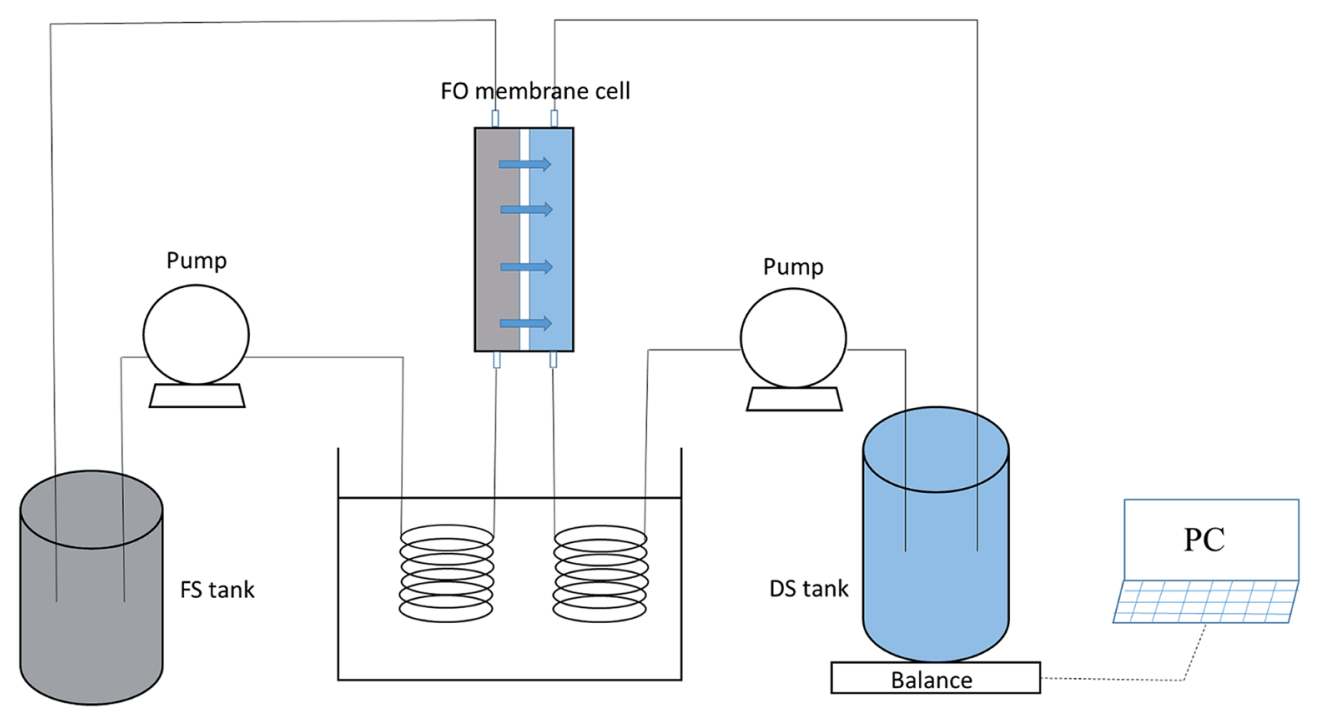

Fig. 2 Schematic diagram of the lab-scale FO experimental set-up. 
where, $R$ is the solute rejection and $C_{\mathrm{p}}$ and $C_{\mathrm{f}}$ are the solute concentrations of the permeate and feed water, respectively.

\section{Results and discussion}

\subsection{Properties of PESA}

PESA has been proven to have large molecular, good water soluble, non-toxic, and biodegradable features, and its chemical<smiles>[M]OC(=O)C(C(C)(C)O)C(C)(C)C(=O)O[Na]</smiles>

Notes: $\mathrm{n}=2-10, \mathrm{M}: \mathrm{Na}^{+}, \mathrm{H}^{+}, \mathrm{K}^{+}$or $\mathrm{NH}_{4}^{+}$

Fig. 3 Chemical structure of PESA. structure is shown in Fig. 3. It can be seen that PESA has an expanded structure, which contributes to a low reverse solute flux and easy solute regeneration in the post treatment. Fig. 4 shows the PESA properties at different concentrations, including $\mathrm{pH}$, conductivity, viscosity, and osmotic pressure. It is shown that the $\mathrm{pH}$ of PESA ranges from $9.34\left(0.5 \mathrm{~g} \mathrm{~mL}^{-1}\right)$ to 8.87 $\left(2 \mathrm{~g} \mathrm{~mL}^{-1}\right.$ ) and it decreases with concentration (Fig. 4(a)). The recommended operational $\mathrm{pH}$ range of the TFC-FO membrane is from 2.0 to $12.0 .^{38}$ Thus, the membrane will not undergo structural changes in the FO process. As shown in Fig. 4(b), the conductivity of PESA is directly proportional to concentration, which is in agreement with the previous study using organic salts as the DS. ${ }^{39}$ This phenomenon shows that PESA dissociates well in water, which is enhanced with concentration. The electrical conductivity of PESA may be derived from the dissociation of ions and outer coordination spheres. The relative viscosity of PESA is shown in Fig. 4(c). The results show that the viscosity increases with an increase in concentration. At the same concentration, the PESA solution at a higher temperature exhibits a smaller value of $\eta_{\gamma}$. A high viscosity of DS has a bad effect on fluid flow through the membrane and results in severe internal polarization concentration. ${ }^{\mathbf{1 4}}$ Compared to the
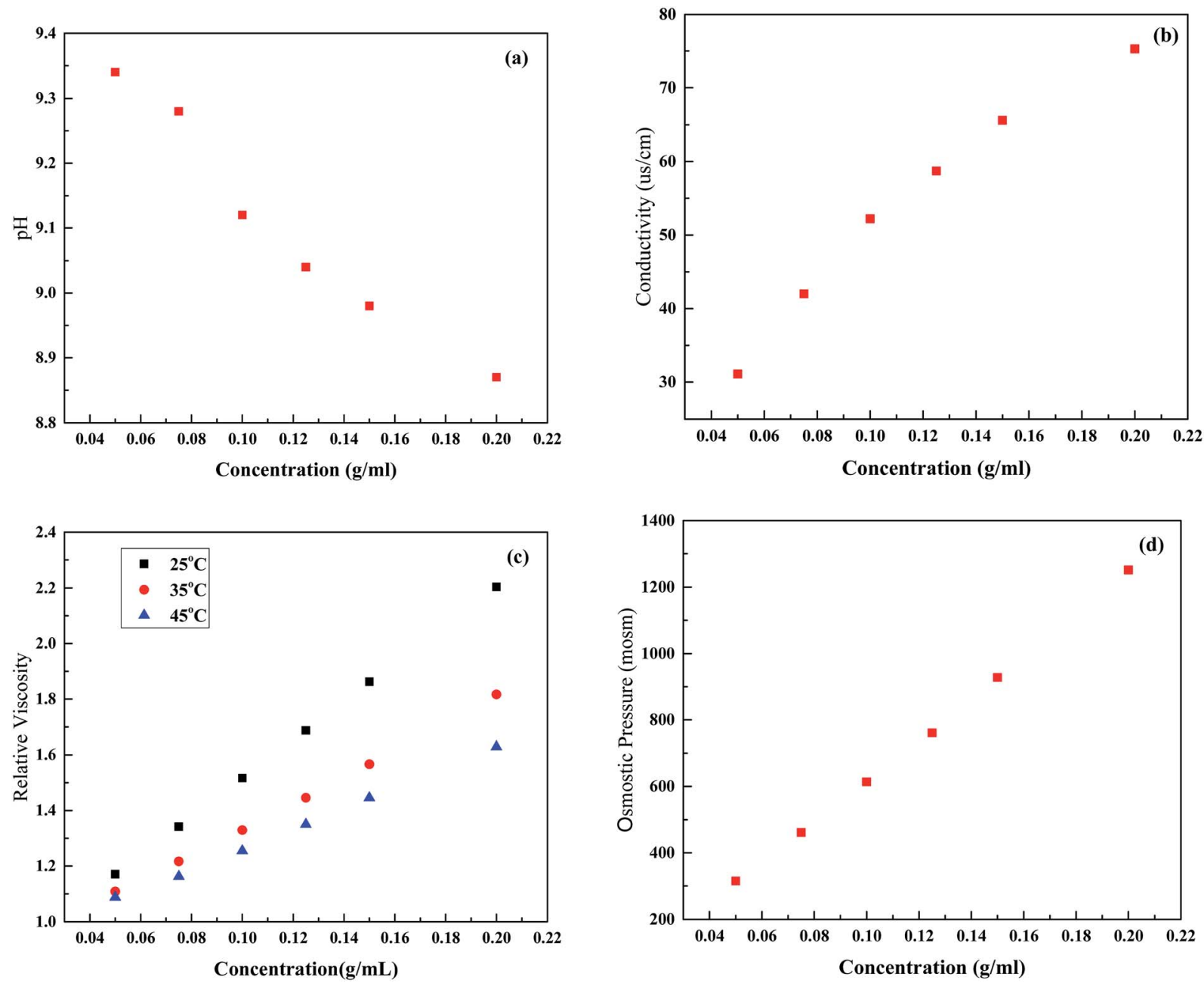

Fig. 4 Characteristics of the PESA draw solution. (a) $\mathrm{pH}$, (b) conductivity, (c) relative viscosity and (d) osmotic pressure. 
polyelectrolyte PAA (2-3 at a concentration of $\left.0.12 \mathrm{~g} \mathrm{~mL}^{-1}\right)$, PESA ( $\sim 1.8$ at a concentration of $0.15 \mathrm{~g} \mathrm{~mL}^{-1}$ ) exhibits a smaller relative viscosity, which shows its advantages as a draw solute. ${ }^{3}$ Fig. 4(d) shows the osmotic pressure of PESA at different concentrations. It can be seen that the osmotic pressure has an almost linear correlation with concentration from 0.5 to $2 \mathrm{~g}$ $\mathrm{mL}^{-1}$. High osmotic pressure is associated with high conductivity, which is in agreement with Fig. 4(b).

PESA is a green corrosion scale inhibitor which has been used in many cooling water systems and shows excellent scale performance. ${ }^{40}$ Generally, the concentration of PESA in cooling systems varies from a few milligrams per liter to a few tens of milligrams per liter. Thus, it is necessary to add pure water to the diluted PESA solution to adjust its concentration. Besides, PESA has been proven to be suitable for high temperature and high $\mathrm{pH}$ conditions, thus it can be used without adjusting the pH unless there is a special need. ${ }^{\mathbf{4 1 - 4 3}}$ Furthermore, there are many processes such as membrane distillation, ultrafiltration, and nanofiltration for the regeneration of the PESA solution. ${ }^{33,34}$ The overall properties of PESA indicate its great potential as an alternative draw solution.

\subsection{Basic FO performance}

In order to confirm the feasibility of using PESA as a draw solution in the FO process, the basic FO performance including water flux and reverse solute flux of PESA was firstly measured. Fig. 5 represents the effect of PESA concentration on water flux and reverse solute flux using DI water as the feed solution on the performance of the FO process. The temperature was $25^{\circ} \mathrm{C}$ and the cross flow rate was $17 \mathrm{~cm} \mathrm{~s}^{-1}$. As shown in Fig. 5(a), in both the PRO and FO modes, the water flux increased trend when the PESA concentration increased from 0.05 to $0.2 \mathrm{~g} \mathrm{~mL}^{-1}$. A higher draw solution concentration could generate a larger osmotic driving force, which leads to a higher water flux across the membrane. ${ }^{44}$ However, the increase in water flux was not directly proportional to PESA concentration, which could be explained by concentration polarization. The higher concentration of PESA reduced its diffusivity, thus leading to serious concentration polarization, which resulted in a non-linear relationship between concentration and water flux. Besides, it can be seen that the $\mathrm{pH}$ of PESA decreases with an increase in concentration (Fig. 4(a)). PESA ionizes when it is dissolved in water, and the ionization of PESA in water increases with $\mathrm{pH}^{45}$ which influences the osmotic pressure and leads to a non-linear variation in water flux. Similarly, as shown in Fig. 5(b), the reverse solute flux also increased when the PESA concentration increased from 0.05 to $0.2 \mathrm{~g} \mathrm{~mL}^{-1}$ following the same trend as that of water flux. The maximum water flux was considered as 15.40 LMH at the concentration of $0.2 \mathrm{~g} \mathrm{~mL}^{-1}$ under the PRO mode and the minimum reverse solute flux was recorded as 3.19 gMH at the concentration of $0.05 \mathrm{~g} \mathrm{~mL}^{-1}$ under the FO mode. The specific reverse solute flux $\left(J_{\mathrm{s}} / J_{\mathrm{w}}\right)$ refers to the ratio of reverse solute flux to water flux, which is used as an indicator of DS loss per volume of water permeation in the FO process. Fig. 5(c) shows the specific reverse solute flux $\left(J_{\mathrm{s}} / J_{\mathrm{w}}\right)$ in terms of PESA concentration in both the PRO and FO modes, where it is
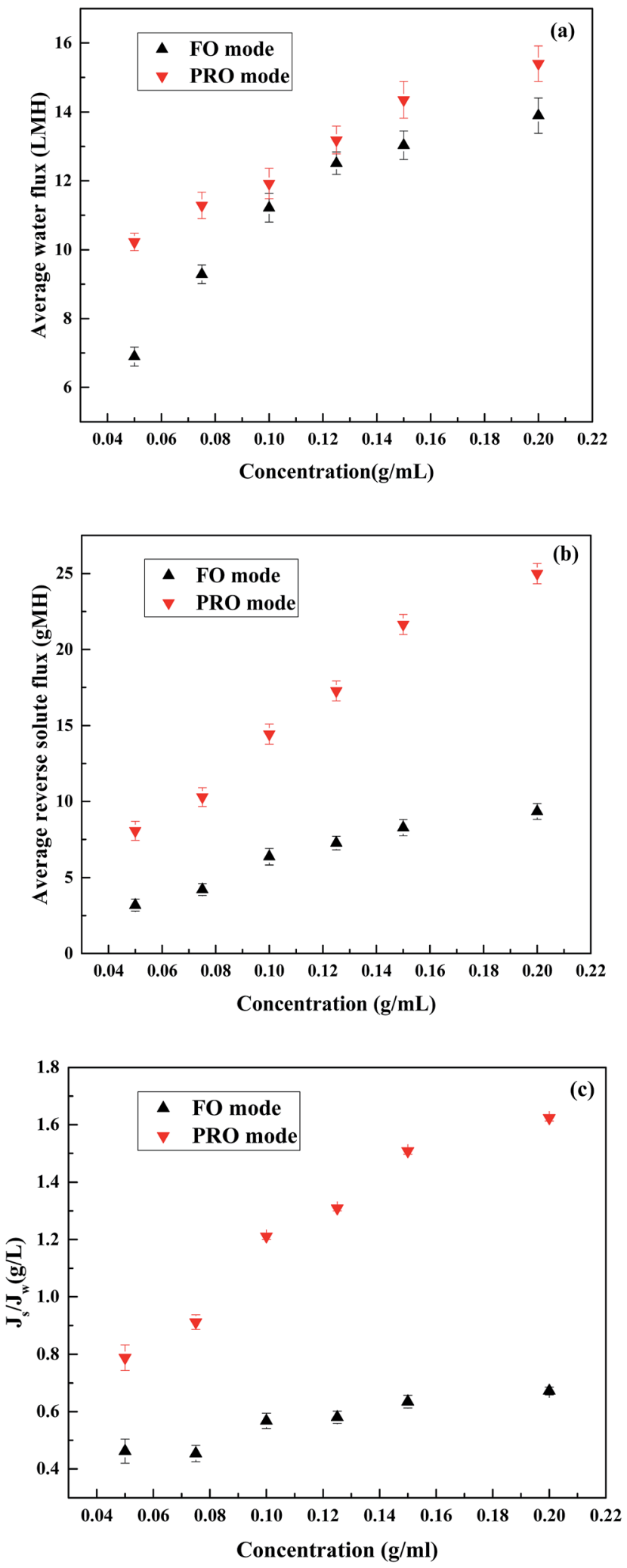

Fig. 5 Effect of PESA draw solution concentration on FO performance at different membrane orientations. (a) Water flux, (b) reverse solute flux and (c) specific reverse solute flux at $25^{\circ} \mathrm{C}$ and $17 \mathrm{~cm} \mathrm{~s}^{-1}$. 
found that the specific reverse solute flux increases independently of concentration under both membrane orientations. It can be seen that all the $J_{\mathrm{s}} / J_{\mathrm{w}}$ vales are higher than that in previous studies ${ }^{3,31}$ which may be due to differences in the membrane structure because the membranes used in our studies were homemade membranes.

\subsection{Comparison of PESA, PASP and NaCl}

To compare the FO performance of PESA, $\mathrm{NaCl}$ (an extensively used inorganic salt) and PASP (a recently reported polyelectrolyte), FO experiments were conducted using $0.05 \mathrm{~g} \mathrm{~mL}^{-1}$ as the model DS concentration and DI water as the feed solution at a temperature of $25^{\circ} \mathrm{C}$ and cross flow rate of $17 \mathrm{~cm} \mathrm{~s}^{-1}$. The osmotic pressure of $0.05 \mathrm{~g} \mathrm{~mL}^{-1} \mathrm{NaCl}$, PASP and PESA was 1437, 652 and $315 \mathrm{mOsm}$, respectively. $0.05 \mathrm{~g} \mathrm{~mL}^{-1}$ PESA had a lower osmotic pressure than PASP, and both of them were less than $\mathrm{NaCl}$. As observed in Fig. 6(a), the water flux difference followed the order $\mathrm{NaCl}>$ PASP $>$ PESA. Although $\mathrm{NaCl}$ had an obviously
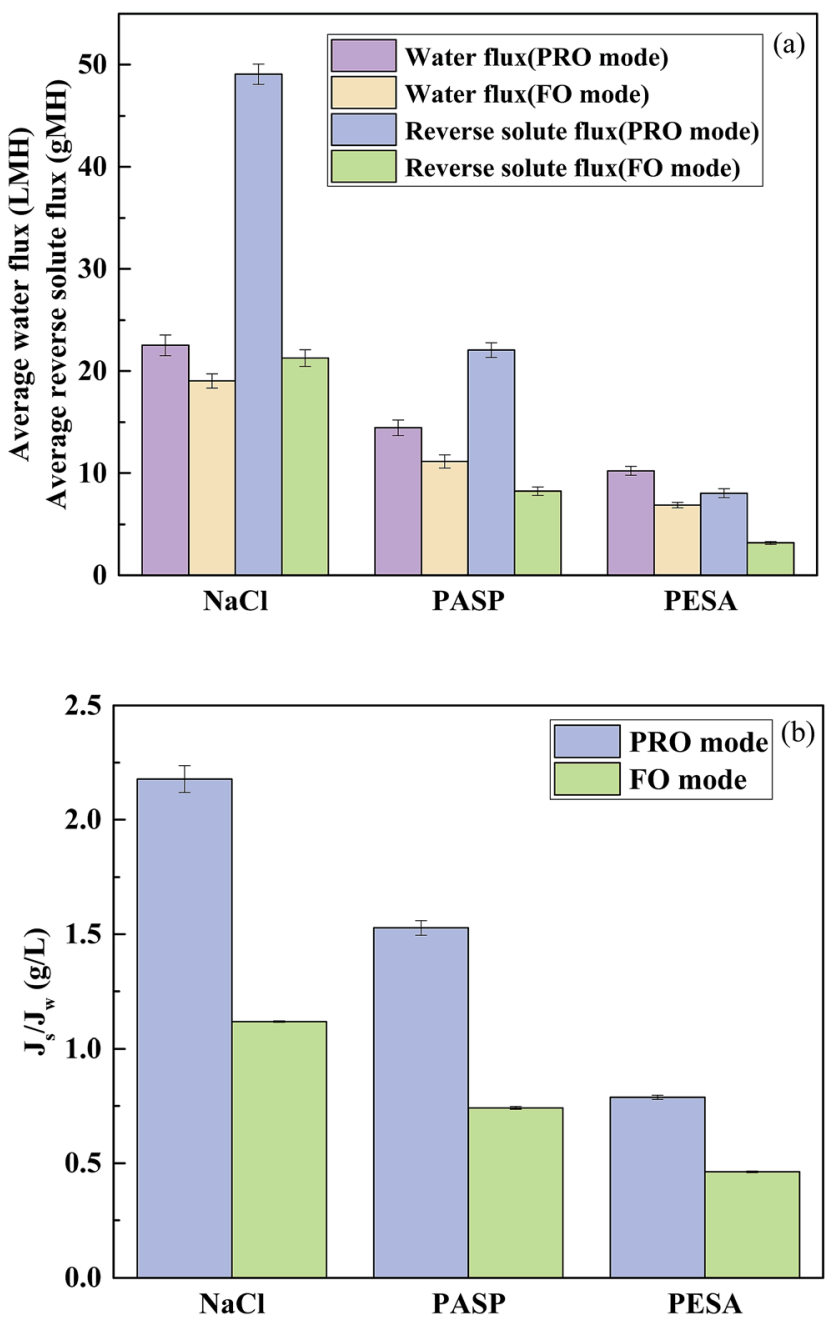

Fig. 6 Performance comparison of PESA $\left(0.05 \mathrm{~g} \mathrm{~mL}^{-1}\right)$ with two draw solutions, specifically $\mathrm{NaCl}\left(0.05 \mathrm{~g} \mathrm{~mL}^{-1}\right)$ and PASP $\left(0.05 \mathrm{~g} \mathrm{~mL}^{-1}\right)$. (a) Water flux and reverse solute flux and (b) specific reverse solute flux, at $25^{\circ} \mathrm{C}$ and $17 \mathrm{~cm} \mathrm{~s}^{-1}$. higher water flux compared to that of PASP and PESA, its large reverse solute flux is an issue, especially in the PRO mode. PASP had higher water flux than PESA which could be simply explained by the osmotic pressure difference between these two solutions. ${ }^{46}$ Although the same concentration was used, the osmotic pressure of $0.05 \mathrm{~g} \mathrm{~mL}^{-1}$ PASP (652 mOsm) was higher than that of $0.05 \mathrm{~g} \mathrm{~mL}^{-1}$ PESA (315 mOsm), whereas PESA had an obviously lower reverse solute flux than that of PASP and $\mathrm{NaCl}$. $\mathrm{NaCl}$ had the smallest molecular weight and thus the largest reverse solute flux. Furthermore, the zeta potential of PESA and PASP was measured. The zeta potential of PESA and PASP was -49.1 and $-14.6 \mathrm{mV}$, respectively. Due to the stronger mutual repulsion of the same charge, the TFC membrane (zeta potential of $-28.75 \mathrm{mV}$, Table 1) is more repulsive to PESA. Thus, the reverse solute flux of PESA is much lower than that of PASP. The loss of draw solutes by reverse diffusion leads to an increase in operational cost due to the replenishment of additional draw solutes, but it should be noted that a high water flux always occurs with a high reverse solute flux. Thus, we need to consider the specific reverse solute flux. As shown in Fig. 6(b), PESA had the lowest $J_{\mathrm{s}} / J_{\mathrm{w}}$ value at both membrane orientations, for example in the FO mode the $J_{\mathrm{s}} / J_{\mathrm{w}}$ value of PESA was $0.46 \mathrm{~g}$ $\mathrm{L}^{-1}$, whereas that of $\mathrm{NaCl}$ and PASP was recorded as 1.12 and $0.74 \mathrm{~g} \mathrm{~L}^{-1}$, respectively. These results indicate that PESA has lower loss to the feed side than $\mathrm{NaCl}$ and PASP for each liter of water produced in the FO process, which would greatly reduce the replenishment cost of the PESA draw solute.

\subsection{Effect of temperature and cross flow rate on water flux}

In order to determine the influence of temperature and cross flow rate on water flux using PESA as DS, FO experiments were conducted under different membrane orientations, temperatures and cross flow rates.

3.4.1 Effect of temperature on water flux. To evaluate the influence of temperature in the FO process, FO experiments were conducted at different draw solution concentrations $(0.05$, 0.1 and $\left.0.15 \mathrm{~g} \mathrm{~mL}^{-1}\right)$, temperatures $\left(25^{\circ} \mathrm{C}, 35^{\circ} \mathrm{C}\right.$ and $\left.45^{\circ} \mathrm{C}\right)$ and membrane orientations (PRO and FO modes) and the cross flow rate was maintained at $17 \mathrm{~cm} \mathrm{~s}^{-1}$. Fig. 7 shows the variation in water flux with temperature during operation in the PRO and FO modes. As the temperature increased from room temperature to $45^{\circ} \mathrm{C}$, the water flux also increased. This is mainly due to the increased osmotic pressure and diffusion coefficient, and decreased viscosity of the solutions at high temperature, which can be seen in Fig. 4. For the feed side, the enhanced temperature increased the diffusion coefficient and at the same time decreased the viscosity, which resulted in an increase in the water-transporting kinetics. For the draw side, the enhanced temperature increased the osmotic pressure, which led to an improvement in the driving force across the membrane. Besides, the dissociation of PESA should be considered since PESA ionizes when it is dissolved in water. The ionization of PESA in water increases with temperature, which will influence the osmotic pressure and cause the water flux to increase. Specifically, a considerable increase in water flux was observed when the temperature increased from $25{ }^{\circ} \mathrm{C}$ to $35{ }^{\circ} \mathrm{C}$ (in both 

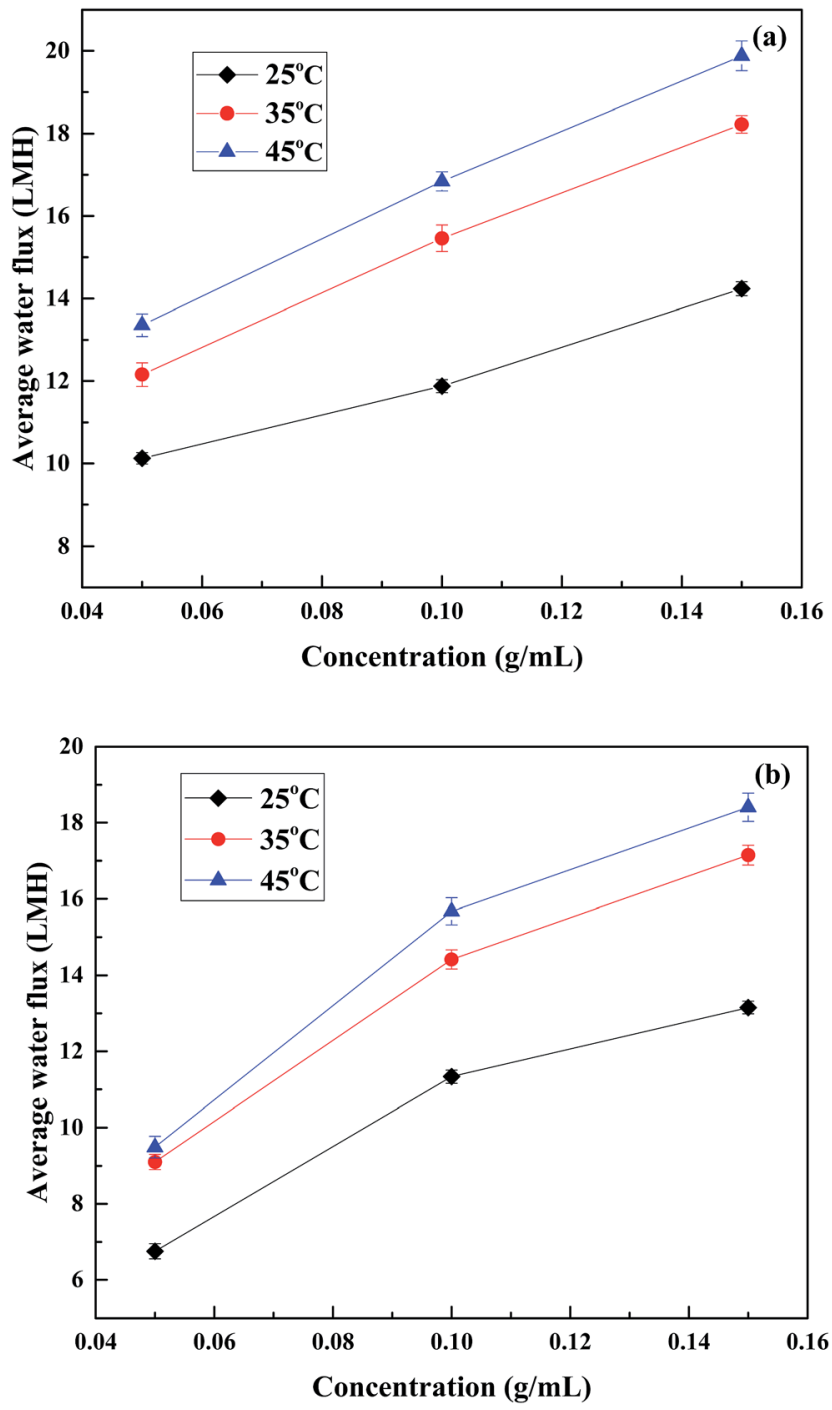

Fig. 7 Effect of temperature on water flux of different concentrations of PESA. (a) PRO mode and (b) FO mode at the cross velocity of $17 \mathrm{~cm} \mathrm{~s}^{-1}$.

PRO and FO modes). However, a slight increase in water flux was observed for the increase in temperature from $35^{\circ} \mathrm{C}$ to $45^{\circ} \mathrm{C}$. The variation tendency was almost the same as that of the relative viscosity presented in Fig. 4 . It can be seen that the relative viscosity decreases obviously with temperature from $25{ }^{\circ} \mathrm{C}$ to $35^{\circ} \mathrm{C}$ compared to the temperature increase from $35^{\circ} \mathrm{C}$ to $45{ }^{\circ} \mathrm{C}$. Increasing the temperature of the draw solute could lead to a decrease in its viscosity and an increase in its diffusion coefficient, which would enhance mass transfer and reduce dilutive external concentration polarization, thus leading to an increase in water flux. ${ }^{4,48}$ This indicates that a small increase in room temperature can result in a considerable water flux. High temperatures can generate high water flux, but this is not economical. It can be also seen that the increase in water flux was not linear with the increase in concentration of PESA, especially in the FO mode. From Fig. 7(b), a considerable increase in water flux was observed for the increase in concentration from 0.05 to $0.1 \mathrm{~g} \mathrm{~mL}^{-1}$, whereas a slight increase in water flux was observed from 0.1 to $0.15 \mathrm{~g} \mathrm{~mL}^{-1}$. This is due to the sudden increase in viscosity between these two concentrations which had a dominating influence compared to the small increase in osmotic pressure. ${ }^{49}$

Thus, it can be concluded that water permeation is susceptible to temperature. In both PRO and FO modes, the increase in water flux from $25{ }^{\circ} \mathrm{C}$ to $35^{\circ} \mathrm{C}$ was more obvious than that from $35{ }^{\circ} \mathrm{C}$ to $45^{\circ} \mathrm{C}$. Therefore, in terms of economy and utility, it is best to control the temperature below $35^{\circ} \mathrm{C}$ when using PESA as the draw solution in the FO process.

3.4.2 Effect of cross flow rate on water flux. To determine whether the cross flow rate of the PESA draw solution and feed solution could improve the water flux, a wide range of velocities (8.5, 17 and $\left.25.5 \mathrm{~cm} \mathrm{~s}^{-1}\right)$ was used in the FO operation, where the temperature was maintained at $25{ }^{\circ} \mathrm{C}$ and three different DS concentrations $\left(0.05,0.1\right.$ and $\left.0.15 \mathrm{~g} \mathrm{~mL}^{-1}\right)$ were chosen. The results in Fig. 8 show that the water flux at high velocities was
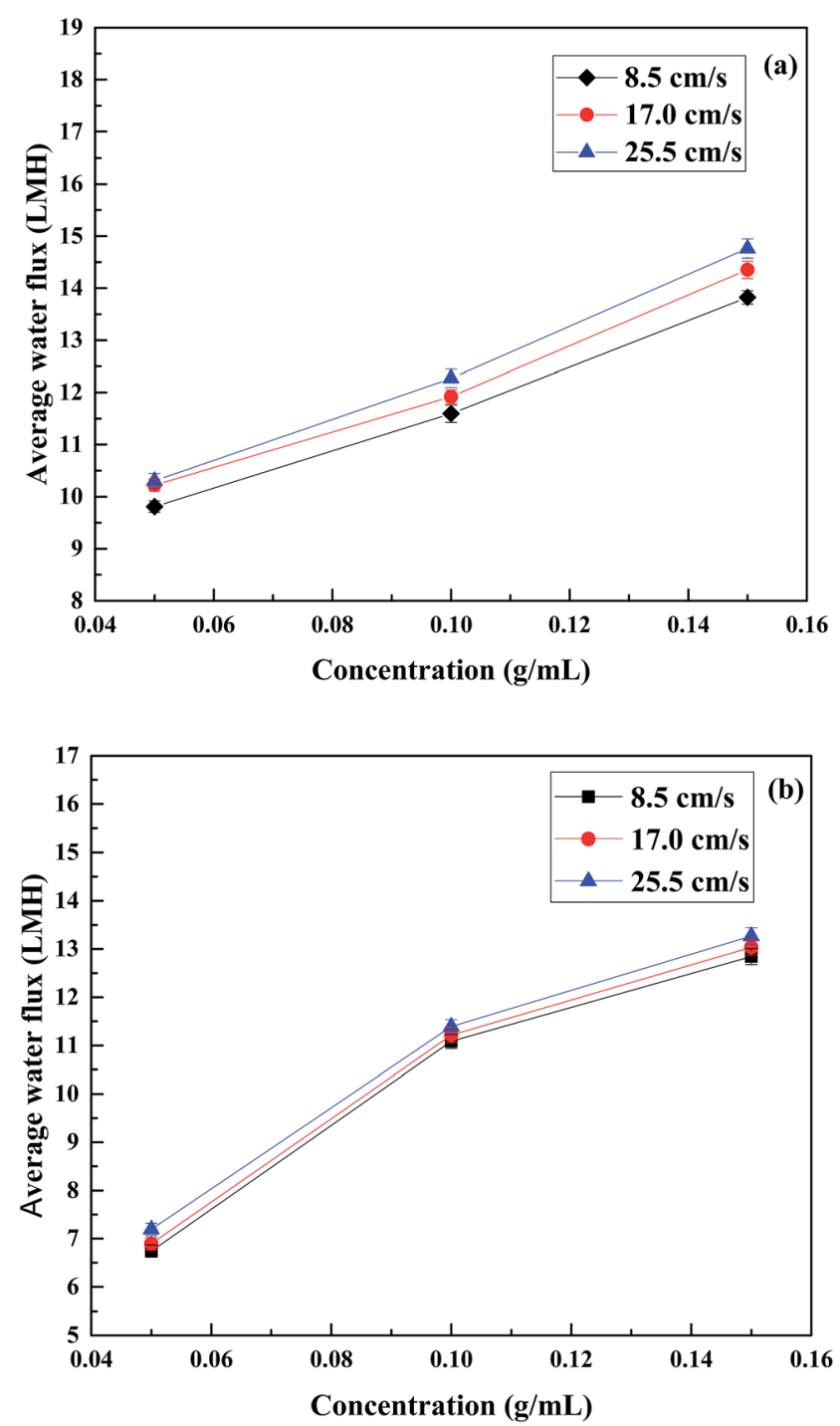

Fig. 8 Effect of cross flow velocity on water flux of different concentrations of PESA. (a) PRO mode and (b) FO mode at the temperature of $25^{\circ} \mathrm{C}$. 
higher than that at low cross velocities. However, the water flux difference in the FO mode was minor at the three cross flow rates which was different from that in a previous study. ${ }^{37}$ In the case of $0.05 \mathrm{~g} \mathrm{~mL}^{-1}$ in the FO mode, the water flux was about $6.74 \mathrm{LMH}$ at the cross flow velocity of $8.5 \mathrm{~cm} \mathrm{~s}^{-1}$, and the flux value was only $2.22 \%$ and $6.68 \%$ higher at a cross flow velocity of 17 and $25.5 \mathrm{~cm} \mathrm{~s}^{-1}$, respectively. For the concentrations of 0.1 and $0.15 \mathrm{~g} \mathrm{~mL}^{-1}$, the water flux increased by $1.17 \%$ and $2.79 \%$ $\left(0.1 \mathrm{~g} \mathrm{~mL}^{-1}\right)$ and $1.48 \%$ and $3.27 \%\left(0.15 \mathrm{~g} \mathrm{~mL}^{-1}\right)$ at a cross flow velocity of 17 and $25.5 \mathrm{~cm} \mathrm{~s}^{-1}$ compared to that at $8.5 \mathrm{~cm} \mathrm{~s}^{-1}$. In the FO mode, the membrane active layer faces the FS and the support layer faces the DS, which lead to concentrative external concentration polarization (CECP) and dilutive internal concentration polarization (DICP). For the feed side, the enhanced cross flow rate increased turbulent flow as a result the weakened CECP ${ }^{48}$ whereas in the draw side, the high cross flow rate increased turbulent flow between the bulk solution and the membrane surface leading to back diffusion of the salts to the bulk solution..$^{50}$ Thus, DICP in the support layer was alleviated. The overall results led to a slight water flux difference under the FO mode.

In the PRO mode, the water flux difference at three flow rates was slightly more obvious compared to that in the FO mode. In the case of $0.05 \mathrm{~g} \mathrm{~mL}^{-1}$, the water flux was about $9.81 \mathrm{LMH}$ at the cross flow velocity of $8.5 \mathrm{~cm} \mathrm{~s}^{-1}$, and the flux value was $4.18 \%$ and $4.99 \%$ higher at a cross flow velocity of 17 and $25.5 \mathrm{~cm} \mathrm{~s}^{-1}$, respectively. For the concentrations of 0.1 and $0.15 \mathrm{~g} \mathrm{~mL}^{-1}$, the water flux increased by $2.85 \%$ and $5.87 \%(0.1 \mathrm{~g}$ $\left.\mathrm{mL}^{-1}\right)$ and $3.84 \%$ and $6.81 \%\left(0.15 \mathrm{~g} \mathrm{~mL}^{-1}\right)$ at a cross flow velocity of 17 and $25.5 \mathrm{~cm} \mathrm{~s}^{-1}$ compared to $8.5 \mathrm{~cm} \mathrm{~s}^{-1}$. In PRO mode, the active layer faces the DS and the support faces the FS, which lead to dilutive external concentration polarization (DECP) and concentrative internal concentration polarization (CICP). For the draw side, similarly to the feed side in the FO mode, the increased cross flow rate reduced DECP. In the feed side, increasing the flow rate increased turbulent flow and promoted back diffusion of the salts from the porous medium to the bulk feed solution. Thus, the driving force across the membrane increased which resulted in a higher water flux. ${ }^{\mathbf{5 0 , 5 1}}$ Indeed, the increased water flux is attributed to the reduction of CICP. Thus, a high flow rate in the PRO mode is preferable when using PESA as the draw solute.

\subsection{Application of PESA in FO for wastewater treatment}

3.5.1 Dyeing wastewater treatment. The feasibility of using FO to treat dyeing wastewater was studied using synthetic dyeing water as the FS and PESA solution at a concentration of $0.15 \mathrm{~g} \mathrm{~mL}^{-1}$ as the DS under the FO mode with the temperature of $25{ }^{\circ} \mathrm{C}$ and flow rate of $17 \mathrm{~cm} \mathrm{~s}^{-1}$ and the results are shown in Fig. 9. Fig. 9(a) and (b) represent K-GL and RGFL, respectively. It can be seen (Fig. 9(a)) that the water flux of PESA achieved balance in $20 \mathrm{~min}$, which indicates that the water flux of PESA as the DS to treat dyeing wastewater is fairly stable. An ultraviolet visible spectrophotometer $\left(\mathrm{UV}_{254}\right.$, Puxi General Instrument Co. Ltd., Beijing, China) was used to detect the dye content in DS, and the results show that the content of dye was zero. This indicates that the dye rejection of the TFC-FO membrane was almost as high as 1 . The fouled membrane was cleaned by freshwater for $1 \mathrm{~h}$ and then used to test water flux under the same conditions. As shown in Fig. 9, the water flux of the cleaned membrane (restored to about 97\%) was almost the same as that of the pristine membrane. These results show that the membrane fouling in the process is reversible, and the water flux well recovered after flushing the membrane with freshwater. A similar trend was obtained in Fig. 9(b) using RGFL as the feed solution. The water flux was stable and the water flux of the cleaned membrane was restored to about $97 \%$ after cleaning with freshwater for $1 \mathrm{~h}$. However, when the $\mathrm{UV}_{254}$ was used to detect the dye content in the diluted DS, the measured absorbance value was 0.125 , which is due to the small molecular weight and good diffusion properties of the disperse dyes. However, according to the standard curve of Disperse yellow at different concentrations, the concentration of RGFL in DS was $14 \mathrm{mg} \mathrm{L}{ }^{-1}$ which is almost negligible. ${ }^{32}$ In order to have a clear observation of the membrane fouling, the SEM images of the cake layer are shown in Fig. 9. Fig. 9(c) and (d) display the images of K-GL and RGFL, respectively. It can be seen that K-GL is more compact and RGFL is more dispersed on the membrane. This due to the fact that RGFL has a lower molecular weight than K-GL, which leads to the dispersed state on the membrane. The overall performances show the advantages of using PESA as the DS in the FO process to treat dyeing water with stable water flux, high dye rejection and reversible membrane fouling.

3.5.2 Brackish water desalination. For the brackish water desalination study, a PESA solution with the concentration of $0.2 \mathrm{~g} \mathrm{~mL}^{-1}$ as the DS and synthetic brackish water $(0.3 \mathrm{M} \mathrm{NaCl})$ as the feed solution were selected for use in the FO process at $25{ }^{\circ} \mathrm{C}$. The variation in water flux in the entire $3 \mathrm{~h}$ is shown in Fig. 10, which compares the baseline when DI water was used as the feed solution under the same conditions $\left(0.2 \mathrm{~g} \mathrm{~mL}^{-1}\right.$ PESA and $25{ }^{\circ} \mathrm{C}$ ). The desalination study was performed under the PRO mode. It can be seen that a considerable decline in water flux was observed when brackish water replaced DI water as the FS. A similar trend was observed by the previous studies using seawater as the feed solution. ${ }^{49}$ This may be due to the fact that brackish water generates a higher osmotic pressure than that of DI water, which reduces the osmotic pressure difference between the draw side and the feed side and leads to a drop in the water flux. In order to further investigate the feasibility of FO for brackish water desalination, the stability of the FO performance in terms of water flux was studied. Three FO tests were conducted under the same conditions $(0.2 \mathrm{~g}$ $\mathrm{mL}^{-1}$ PESA, $25{ }^{\circ} \mathrm{C}$ and $17 \mathrm{~cm} \mathrm{~s}^{-1}$ ) using the same membrane and the fouled membrane was cleaned by physically flushing freshwater through the fouled polyamide surface for $1 \mathrm{~h}$ after each test. As shown in Fig. 11, a very stable and reproducible water flux was achieved. Compared to the first test, the average water flux of the second and third tests was restored to about $96.2 \%$ and $93.2 \%$, respectively. This indicates that simple physical flushing can effectively rejuvenate the fouled membrane and the average water flux can be restored to about $93.2 \%$ even after 3 cycles. This again demonstrates the 

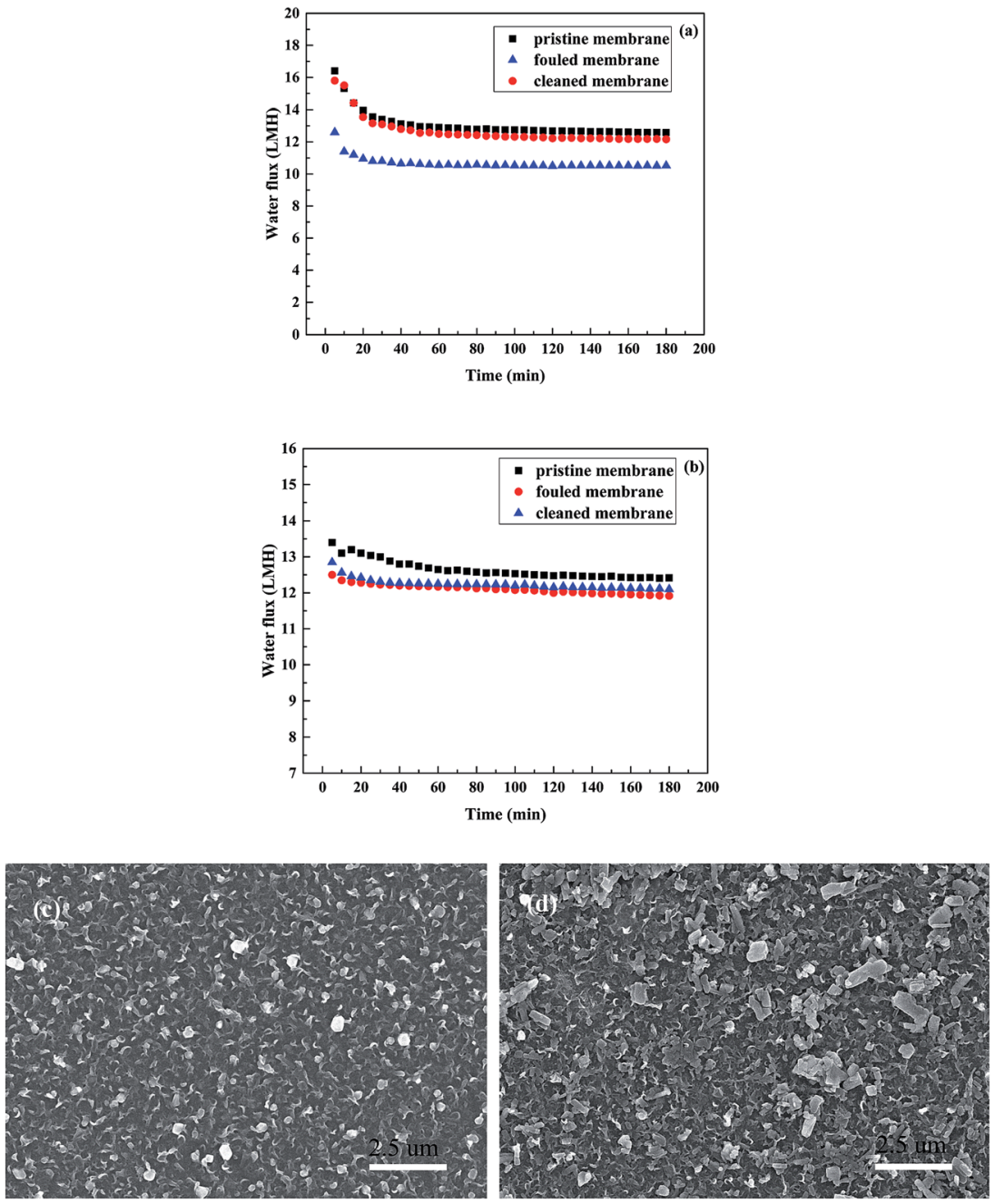

Fig. 9 Water flux variation using PESA $\left(0.15 \mathrm{~g} \mathrm{~mL}^{-1}\right)$ as the DS in the FO process to treat dyeing wastewater. (a) Reactive blue and (b) disperse yellow at the temperature of $25^{\circ} \mathrm{C}$ and flow rate of $17 \mathrm{~cm} \mathrm{~s}^{-1}$ in the FO mode. SEM images of the cake layer of (c) K-GL and (d) the RGFL.

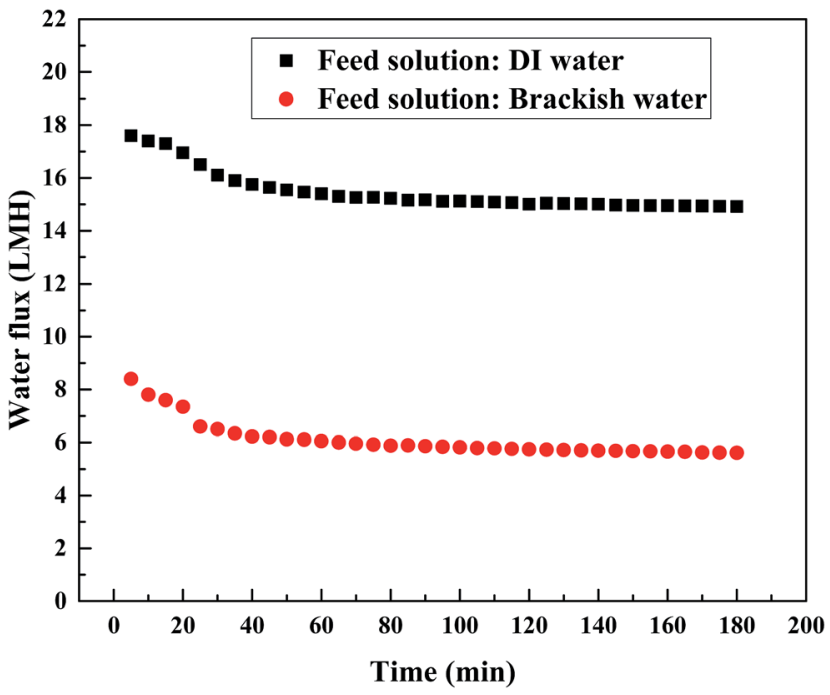

Fig. 10 Comparison of the PESA performance in terms of water flux with DI water and brackish water as feed solutions and $0.2 \mathrm{~g} \mathrm{~mL}^{-1}$ PESA as the draw solution in the PRO mode at the temperature of $25^{\circ} \mathrm{C}$ and velocity of $17 \mathrm{~cm} \mathrm{~s}^{-1}$.

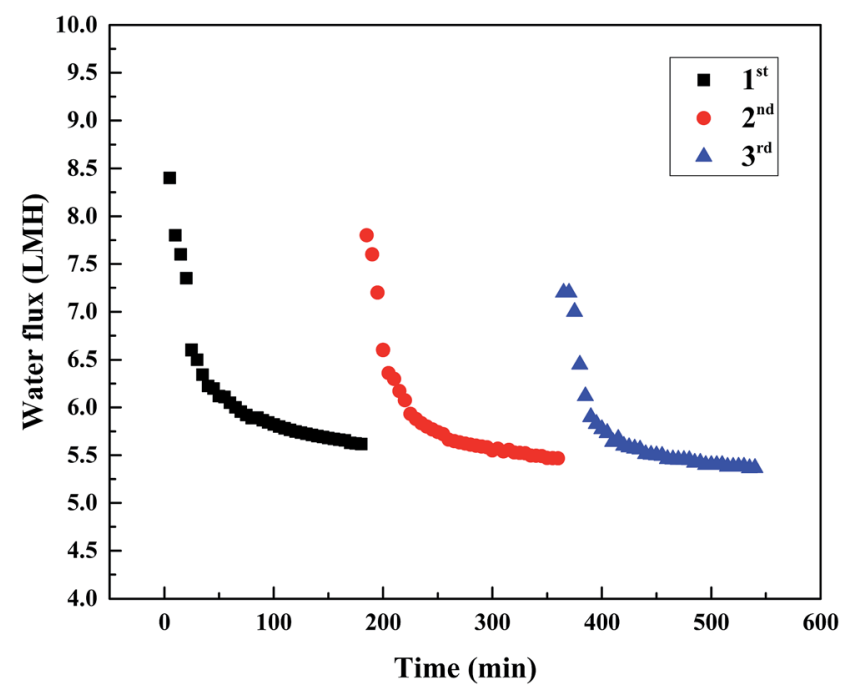

Fig. 11 Reduction in water flux with time in the PRO mode using brackish water as the feed solution and $0.2 \mathrm{~g} \mathrm{~mL}^{-1}$ PESA as the draw solution. Membranes were cleaned by physical flushing for $1 \mathrm{~h}$ and then reused. 


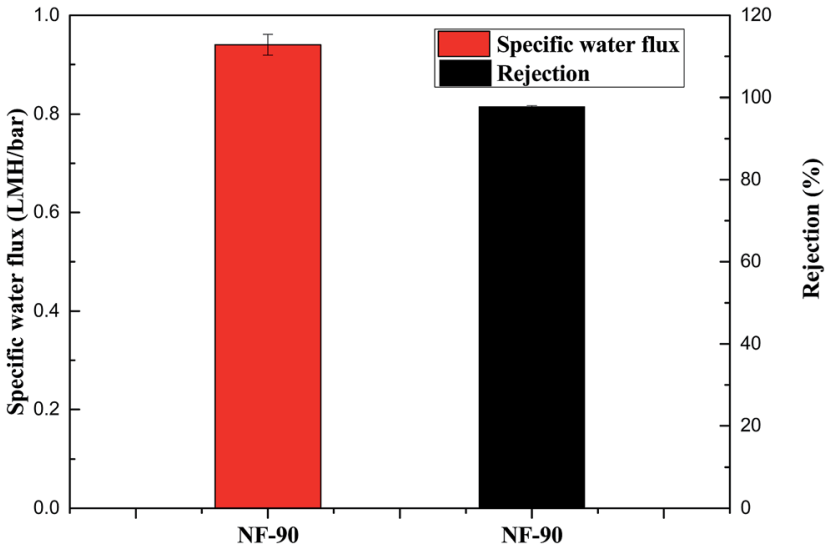

Fig. 12 Recovery of PESA solution using the NF-90 membrane (pressure: 20 bar; diluted PESA solution concentration: $0.03 \mathrm{~g} \mathrm{~mL}^{-1}$ and temperature: $25 \pm 1{ }^{\circ} \mathrm{C}$ ).

potential of using PESA as the draw solute for brackish water desalination.

\subsection{Recovery of PESA draw solution via NF}

In order to investigate the feasibility of PESA recovery, a recovery study was conducted using a pressure-driven NF process. A dilute PESA solution with a concentration of $0.03 \mathrm{~g} \mathrm{~mL}^{-1}$ was used as the feed solution. The experiments were conducted at the operating pressure of $20 \mathrm{bar}$ and temperature of $25 \pm 1{ }^{\circ} \mathrm{C}$. The specific water flux refers to the ratio of water flux to hydraulic pressure, which is used as an indicator of recovery efficiency. As shown in Fig. 12, the specific water flux and the PESA solute rejection rate were 0.94 LMH per bar and 97.8\%, respectively. According to the procedure by Gwak et al. ${ }^{31} 0.03 \mathrm{~g}$ $\mathrm{mL}^{-1}$ PASP solution was used as the NF feed solution and its specific water flux and rejection rate were $0.4 \mathrm{LMH}$ per bar and 98.9\%, respectively. Compared to the PASP solution, the PESA solution had a better specific water flux performance and comparable rejection rate. To improve the rejection rate, other recovery methods such as membrane distillation should be further investigated.

\section{Conclusion}

In this study, the polyelectrolyte PESA was applied as the draw solute in the FO process. Its characteristics of high solubility in water, expanded molecular structure, low viscosity, non-toxicity, and relatively high osmotic pressure could provide favorable FO performances and easy solute regeneration in post treatments. Furthermore, the diluted PESA solution could be used in many cooling water systems since PESA is a green scale inhibitor. The FO performances of PESA, PASP and $\mathrm{NaCl}$ were studied and compared. The influence of concentration, temperature, cross flow velocity and membrane orientation on FO performance using PESA as the draw solute was investigated. Besides, $0.2 \mathrm{~g}$ $\mathrm{mL}^{-1}$ PESA was chosen as a representative for dyeing wastewater treatment and brackish water desalination. The recovery experiments were conducted using the NF process with $0.03 \mathrm{~g}$ $\mathrm{mL}^{-1}$ PESA as the feed solution.
Compared to PASP and $\mathrm{NaCl}$, the loss of PESA in recovering a liter of water from the feed side was low, which not only reduces contamination in the feed side but also saves the replenishment cost of the PESA draw solute. The effect of temperature on water flux was obvious, but the increase in water flux from $35{ }^{\circ} \mathrm{C}$ to $45{ }^{\circ} \mathrm{C}$ was much less than that from $25{ }^{\circ} \mathrm{C}$ to $35^{\circ} \mathrm{C}$ in both the PRO and FO modes. Therefore, from the point of view of energy conservation it is preferable to conduct the FO process at a temperature below $35{ }^{\circ} \mathrm{C}$. An increased cross flow velocity could promote water flux but its influence was minor in the FO mode. Compared to the FO mode, the water flux difference under three flow rates was more obvious in the PRO mode due to the reduction of CICP. Thus, a high flow rate in the PRO mode is preferable when using PESA as the draw solute. The use of PESA as the DS in the FO process to treat dyeing water shows the advantages of stable water flux, high dye rejection and reversible membrane fouling. Moreover, the NF process indicates the good performance of PESA recovery with a high specific water flux (0.94 LMH per bar) and rejection rate (97.8\%). Thus, the overall performance of PESA demonstrates that it is a promising draw solute.

\section{Acknowledgements}

This work was supported by the Taishan Scholar Program (No. ts201511003).

\section{References}

1 M. Elimelech and W. A. Phillipt, Science, 2011, 333, 712-717.

2 M. A. Montgomery and M. Elimelech, Environ. Sci. Technol., 2007, 41, 17-24.

3 Q. Ge, J. Su, G. L. Amy and T. S. Chung, Water Res., 2012, 46, 1318-1326.

4 K. P. Lee, T. C. Arnot and D. Mattia, J. Membr. Sci., 2011, 370, 1-22.

5 L. F. Greenlee, D. F. Lawler, B. D. Freeman, B. Marrot and P. Moulin, Water Res., 2009, 43, 2317-2348.

6 D. L. Shaffer, J. R. Werber, H. Jaramillo, S. Lin and M. Elimelech, Desalination, 2015, 356, 271-284.

7 T.-S. Chung, S. Zhang, K. Y. Wang, J. Su and M. M. Ling, Desalination, 2012, 287, 78-81.

8 R. Valladares Linares, Z. Li, S. Sarp, S. S. Bucs, G. Amy and J. S. Vrouwenvelder, Water Res., 2014, 66, 122-139.

9 A. J. Ansari, F. I. Hai, W. Guo, H. H. Ngo, W. E. Price and L. D. Nghiem, Sci. Total Environ., 2016, 566-567, 559-566.

10 K. Lutchmiah, A. R. Verliefde, K. Roest, L. C. Rietveld and E. R. Cornelissen, Water Res., 2014, 58, 179-197.

11 Y. Cai, R. Wang, W. B. Krantz, A. G. Fane and X. M. Hu, RSC Adv., 2015, 5, 97143-97150.

12 J. R. McCutcheon, R. L. McGinnis and M. Elimelech, J. Membr. Sci., 2006, 278, 114-123.

13 A. Sagiv, A. Zhu, P. D. Christofides, Y. Cohen and R. Semiat, J. Membr. Sci., 2014, 464, 161-172.

14 D. Zhao, S. Chen, P. Wang, Q. Zhao and X. Lu, Ind. Eng. Chem. Res., 2014, 53, 16170-16175. 
15 N. T. Hau, S.-S. Chen, N. C. Nguyen, K. Z. Huang, H. H. Ngo and W. Guo, J. Membr. Sci., 2014, 455, 305-311.

16 N. C. Nguyen, S. S. Chen, H. Y. Yang and N. T. Hau, Bioresour. Technol., 2013, 132, 224-229.

17 H. Zhu, L. Zhang, X. Wen and X. Huang, Bioresour. Technol., 2012, 113, 207-213.

18 M. M. Ling and T.-S. Chung, J. Membr. Sci., 2011, 372, 201209.

19 Q. Ge, M. Ling and T.-S. Chung, J. Membr. Sci., 2013, 442, 225-237.

20 A. Zhou, H. Luo, Q. Wang, L. Chen, T. C. Zhang and T. Tao, RSC Adv., 2015, 5, 15359-15365.

21 H. T. Nguyen, N. C. Nguyen, S. S. Chen, H. H. Ngo, W. Guo and C. W. Li, Sci. Total Environ., 2015, 538, 129-136.

22 M. Yasukawa, S. Mishima, Y. Tanaka, T. Takahashi and H. Matsuyama, Desalination, 2017, 402, 1-9.

23 T. P. N. Nguyen, B.-M. Jun and Y.-N. Kwon, J. Membr. Sci., 2017, 523, 111-121.

24 J. Ren and J. R. McCutcheon, Desalination, 2014, 343, 187193.

25 A. Achilli, T. Y. Cath and A. E. Childress, J. Membr. Sci., 2010, 364, 233-241.

26 J. R. McCutcheon, R. L. McGinnis and M. Elimelech, Desalination, 2005, 174, 1-11.

27 D. Li, X. Zhang, G. P. Simon and H. Wang, Water Res., 2013, 47, 209-215.

28 S. Phuntsho, J. E. Kim, M. A. H. Johir, S. Hong, Z. Li, N. Ghaffour, T. Leiknes and H. K. Shon, J. Membr. Sci., 2016, 508, 22-31.

29 Y. Cui, Q. Ge, X.-Y. Liu and T.-S. Chung, J. Membr. Sci., 2014, 467, 188-194.

30 Q. Long, L. Shen, R. Chen, J. Huang, S. Xiong and Y. Wang, Environ. Sci. Technol., 2016, 50, 12022-12029.

31 G. Gwak, B. Jung, S. Han and S. Hong, Water Res., 2015, 80, 294-305.

32 Q. Long and Y. Wang, AIChE J., 2016, 62, 1226-1235.
33 P. Zhao, B. Gao, S. Xu, J. Kong, D. Ma, H. K. Shon, Q. Yue and P. Liu, Chem. Eng. J., 2015, 264, 32-38.

34 J. Duan, E. Litwiller, S.-H. Choi and I. Pinnau, J. Membr. Sci., 2014, 453, 463-470.

35 R. C. Ong, T.-S. Chung, J. S. de Wit and B. J. Helmer, J. Membr. Sci., 2015, 473, 63-71.

36 N. Widjojo, T.-S. Chung, M. Weber, C. Maletzko and V. Warzelhan, Chem. Eng. J., 2013, 220, 15-23.

37 P. Zhao, B. Gao, Q. Yue, S. Liu and H. K. Shon, Desalination, 2016, 378, 67-73.

38 Y. Zhao, Y. Ren, X. Wang, P. Xiao, E. Tian, X. Wang and J. Li, Desalination, 2016, 378, 28-36.

39 S. K. Yen, F. Mehnas Haja, N. M. Su, K. Y. Wang and T.-S. Chung, J. Membr. Sci., 2010, 364, 242-252.

40 D. Liu, W. Dong, F. Li and F. Hui, Desalination, 2012, 304, 110.

41 L. Dangni and T. Bing, Ind. Water Treat., 2012, 32.

42 W. Xiao, P. Ming, W. Shuhai and W. Yaquan, Spec. Petrochem., 2012, 29.

43 L. Xinhua, L. Wenzhi, K. Yichao and W. Qinghui, Surf. Technol., 2010, 39.

44 H. T. Nguyen, S.-S. Chen, N. C. Nguyen, H. H. Ngo, W. Guo and C.-W. Li, J. Membr. Sci., 2015, 489, 212-219.

45 S. Zürcher and T. Graule, J. Eur. Ceram. Soc., 2005, 25, 863873.

46 G. Gadelha, M. S. Nawaz, N. P. Hankins, S. J. Khan, R. Wang and C. Y. Tang, Desalination, 2014, 354, 97-106.

47 S. Phuntsho, S. Vigneswaran, J. Kandasamy, S. Hong, S. Lee and H. K. Shon, J. Membr. Sci., 2012, 415-416, 734-744.

48 J. R. McCutcheon and M. Elimelech, J. Membr. Sci., 2006, 284, 237-247.

49 R. Kumar, S. Al-Haddad, M. Al-Rughaib and M. Salman, Desalination, 2016, 394, 148-154.

50 A. H. Hawari, N. Kamal and A. Altaee, Desalination, 2016, 398, 98-105.

51 S. Phuntsho, S. Sahebi, T. Majeed, F. Lotfi, J. E. Kim and H. K. Shon, Chem. Eng. J., 2013, 231, 484-496. 